\title{
Adapting health care competencies to a formal competency model
}

\author{
Onjira Sitthisak Lester Gilbert Hugh C Davis \\ Learning Societies Lab, School of Electronics and Computer Science \\ Mary Gobbi \\ School of Nursing and Midwifery \\ University of Southampton, Highfield, Southampton, SO17 1BJ, United Kingdom \\ \{os05r,lg3, hcd\}@ecs.soton.ac.ukandmog1@soton.ac.uk
}

\begin{abstract}
Health professions education has moved away from process-based curricula to competency-based curricula. Machine readable and processable health care competencies are still embryonic, pending the emergence of appropriate standards. The IMS Reusable Definition of Competency or Educational Objective specification and the HR-XML competency standard are introduced, compared, and their problems identified in the implementation of exemplar competencies from the UK Royal College of Nursing. An improved competency model is proposed.
\end{abstract}

\section{Introduction}

Nursing has moved away from structure and content-based curricula to competency-based curricula that focus on the expected outcomes of the learning activity and the professional and academic competencies which learners are expected to attain $[1,2]$. This shift requires well-defined practitioner competencies in order to be able to maintain and improve process quality, to flexibly adapt to changed processes and occupational roles, to systematically assess practitioner competencies, and to plan training activities.

In this scenario, the adoption of electronic competency records and their interoperability will be enhanced via adherence to emerging standards for competency definition. The main standards currently include the IMS Reusable Definition of Competency or Educational Objective (IMS RDCEO) specification and the HR-XML standard.

The health care community is only just beginning to make use of these standards. The School of Nursing and Midwifery at the University of Southampton is taking the lead in adapting them to health care in the
mPLAT project (http://www.mplat.ecs.soton.ac.uk/), devoted to advancing health care education through technology standards that promote professional competence, collaboration, and improved patient care.

In this paper, we present an overview of the two major competency standards. We introduce a taxonomy of the different features that can be presented in a competency standard, and compare the standards against the taxonomy. We implement an exemplar RCN competency, identify the problems exposed in these existing standards, and propose a competency model in order to reflect all relevant features of the learner's behaviour and their knowledge, skills, and attitudes that affect their learning and performance.

\section{Competency and existing standards}

Competency is defined as the integrated application of knowledge, skills, values, experience, contacts, external knowledge resources, and tools to solve a problem or to perform an activity [3].

\subsection{IMS RDCEO specification}

The IMS RDCEO Information Model presents competency information in five categories: Identifier, Title, Description, Definition, and Metadata.

Because of the unstructured textual definitions in RDCEO, descriptions of significant competency elements, such as proficiency level, subject matter, and capability, may be included only via the title element. This gives difficulties for machine searching and processing of these elements if they are not held separately from the narrative description. Further, [1] discusses the problem of linking competency to the content of learning materials because of the RDCEO unstructured textual descriptions. Finally, there remain 
problems with the grading scale of a competency, the success threshold of a competency, and the structure of complex competencies within RDCEO [4].

\subsection{HR-XML competency standards}

The HR-XML consortium was established to create an XML schema to support standardized and practical exchange of competencies information within a variety of business contexts.

HR-XML presents competency information in nine categories: Name, Description, Required, CompetencyId, TaxonomyId, CompetencyEvidence, CompetencyWeight, Competency, and UserArea. The HR-XML competency standard is focused on helping an organization improve communication across its HR activities enhancing recruiting systems, rather than on improving the use of competency information in education or training.

\section{Requirements for competency standards}

In this section we list the possible requirements for describing competencies based on an analysis of the general structure of existing competency standards and competency ontologies $[5,6]$. We classify the requirements into nine categories: Description, Type, Relationship, Proficiency level, Measurement scale, Taxonomy, Evidence, Tools, and User area, where each is divided into sub categories. The requirements list is general and captures the types of information modelled in existing standards, rather than defining a canonical set of properties.

\section{Comparison of RDCEO and HR-XML}

Table 1 shows a comparison of the competency standards described.

- IMS RDCEO provides a flexible definition of competency using unstructured textual definitions. However, this leads to shortcomings in domain definition, ontology use, the ability to compare competency data between different communities, and the tracking of the knowledge state of the learner.

- HR-XML addresses some shortcomings of RDCEO as illustrated in Table 1. However, it still misses an important point of competency relations and tools. Although HR-XML provides for competencies to be composed of other competencies, it does not have an element referring to the competency relation. This may cause selection problems. For example, in a competency hierarchy, it should be possible to specify which elements of the competency hierarchy are mandatory and which are optional.
Table 1. A comparison of the capabilities of competency standards

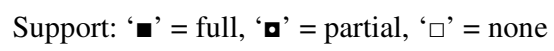

\begin{tabular}{|c|c|c|c|}
\hline Categories & $\begin{array}{c}\text { Sub } \\
\text { Categories }\end{array}$ & $\begin{array}{c}\text { IMS } \\
\text { RDCEO }\end{array}$ & $\begin{array}{l}\text { HR- } \\
\text { XML }\end{array}$ \\
\hline $\begin{array}{l}\text { Competency } \\
\text { description }\end{array}$ & & 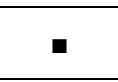 & . \\
\hline \multirow{3}{*}{ Competency type } & Knowledge & - & 口 \\
\hline & Skill & a & a \\
\hline & Attitudes & a & a \\
\hline $\begin{array}{l}\text { Competency } \\
\text { relationship }\end{array}$ & & - & $\square$ \\
\hline Proficiency level & & - & - \\
\hline Measurement scale & & - & - \\
\hline Taxonomy & & 口 & - \\
\hline Evidence & & 口 & - \\
\hline Tools & & 口 & $\square$ \\
\hline User area & & 口 & - \\
\hline
\end{tabular}

\section{An improved competency model}

We focus on how to represent competency as a rich data structure. The heart of this model is to treat knowledge, not as possession, but as a contextualized multidimensional space of capability either actual or potential. The improved competency model is represented in Figure 1and involves three important elements: an orientation towards and focus upon activity-based teaching and learning; the identification and integration of appropriate subject matter content within a broader teaching and learning context represented by a hierarchy of competencies; and the straightforward identification of the assessment that would demonstrate successful teaching and learning.

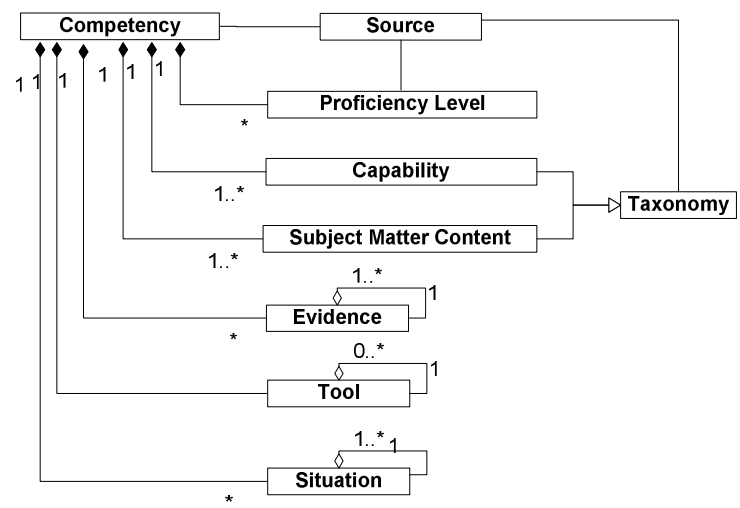

Figure 1. Competency model 
Table 2. A comparison of usability criteria between IMS RDCEO, HR-XML, and the proposed model

\begin{tabular}{|l|l|l|l|}
\hline \multicolumn{1}{|c|}{ Criteria } & \multicolumn{1}{c|}{ IMS RDCEO } & \multicolumn{1}{c|}{ HR-XML } & \multicolumn{1}{c|}{ Proposed model } \\
\hline $\begin{array}{l}\text { Reusability : link to other } \\
\text { competencies }\end{array}$ & $\begin{array}{l}\text { Embeds relation within } \\
\text { competency record }\end{array}$ & $\begin{array}{l}\text { Embeds relation within } \\
\text { competency record }\end{array}$ & $\begin{array}{l}\text { Separates relation from } \\
\text { competency record }\end{array}$ \\
\hline $\begin{array}{l}\text { Reusability : link to } \\
\text { content }\end{array}$ & $\begin{array}{l}\text { Embeds subject matter } \\
\text { content within competency }\end{array}$ & Refers to taxonomy & Refers to taxonomy \\
\hline Interoperability: focus on & Definitions of competency & $\begin{array}{l}\text { Measurement of } \\
\text { competency }\end{array}$ & $\begin{array}{l}\text { Definitions and measurement of } \\
\text { competency }\end{array}$ \\
\hline $\begin{array}{l}\text { Equivalency and } \\
\text { similarity: evidence }\end{array}$ & $\begin{array}{l}\text { Unstructured definition of } \\
\text { evidence element }\end{array}$ & Uses Evidence element & Uses Evidence element \\
\hline $\begin{array}{l}\text { Assessment request: } \\
\text { measurability }\end{array}$ & $\begin{array}{l}\text { Unstructured definition of } \\
\text { weight, threshold and scale }\end{array}$ & Uses Weight element & $\begin{array}{l}\text { Uses scale and threshold of } \\
\text { Proficiency level }\end{array}$ \\
\hline $\begin{array}{l}\text { Assessment request: } \\
\text { measurable behaviours }\end{array}$ & Unstructured definition & $\begin{array}{l}\text { Depends on reference } \\
\text { taxonomy }\end{array}$ & Uses taxonomy of Capability \\
\hline $\begin{array}{l}\text { Defining domain and } \\
\text { scope of ontology }\end{array}$ & $\begin{array}{l}\text { Depends on each system by } \\
\text { using unstructured } \\
\text { definition }\end{array}$ & $\begin{array}{l}\text { Defines structured } \\
\text { definition by using } \\
\text { Description }\end{array}$ & $\begin{array}{l}\text { Defines structured definition by } \\
\text { using Capability, Proficiency, } \\
\text { Situation, Source, Tools, and } \\
\text { Subject matter content }\end{array}$ \\
\hline $\begin{array}{l}\text { Personalization: } \\
\text { tracking knowledge state } \\
\text { of learner }\end{array}$ & $\begin{array}{l}\text { Depends on each system by } \\
\text { using unstructured } \\
\text { definition }\end{array}$ & $\begin{array}{l}\text { Defines structured } \\
\text { definition by using } \\
\text { Description, Weight and } \\
\text { Evidence }\end{array}$ & $\begin{array}{l}\text { Defines structured definition by } \\
\text { using Capability, Proficiency, } \\
\text { Situation, Tools, and Subject } \\
\text { matter content }\end{array}$ \\
\hline
\end{tabular}

Competency modelling needs multi-hierarchies for cross-reference among disciplines [7]. In this proposed competency model, linkages between competencies within a competency hierarchy is separated from the competency records themselves.

\section{Discussion}

We used an RCN competency for a paediatric nurse and implemented it using XML format in IMS RDCEO, HR-XML, and the proposed competency model. Based on our observations, implementation, and metadata principles and practicalities [8], we analyzed how well the existing competency standards and the proposed competency model map to selected criteria of usability, as shown in Table 2.

\section{Conclusion}

We developed and implemented competency-based learning standards using RCN competencies. Existing e-learning competency standards (IMS RDCEO, HRXML) are not able to accommodate complicated competencies, link competencies adequately, support comparisons of competency data between different communities, or support tracking of the knowledge state of the learner. We proposed an improved the competency model.

\section{References}

[1] Hersh, W.R., R.T. Bhupatiraju, P.S. Greene, V. Smothers, and C. Cohen. "Adopting e-learning standards in health care: competency-based learning in the medical informatics domain". in Proceedings of the AMIA. 2006.

[2] Defloor, T., A.V. Hecke, S. Verhaeghe, M. Gobert, E. Darras, and M. Grypdonck, "The clinical nursing competences and their complexity in Belgian general hospitals". Journal of Advanced Nursing, 2006.

[3] Kunzmann, C. "Ontology-based Competence Management for Healthcare Training Planning: A Case Study". in Proceeding of the I-KNOW. 2006. Austria.

[4] Sandberg, R., Competence-the Basis for a Smart Workforce, R. Gerber and C. Lankshear (Eds.) Training for a smart workforce, Editor. 2000, Routledge: London.

[5] Karampiperis, P., D. Sampson, and D. Fytros. "Lifelong Competence Development: Towards a Common Metadata Model for Competencies Description - The Case Study of Europass Language Passport." in Proceedings of the ICALT. 2006.

[6] Schmidt, A. and C. Kunzmann. "Towards a Human Resource Development Ontology for Combining Competence Management and Technology-Enhanced Workplace Learning". in Proceedings of OntoContent. 2006.

[7] Trichet, F. and M. Leclère, A Framework for Building Competency-Based Systems Dedicated to Human Resource Management. Lecture Notes in ComputerScience.

[8] Duval, E., W. Hodgins, S. Sutton, and S.L. Weibel,Metadata Principles and Practicalities, in D-Lib Magazine. 2002. 